\title{
IDENTIFICAÇÃo de Vítimas de DESASTRE PELAS IMPRESSÕES DigitaIS: O ROMPIMENTO DA BARRAGEM DE BRUMADINHO
}

\author{
DISASTER VICTIM IDENTIFICATION USING \\ Fingermarks: The BRUMadinho DAM Collapse
}

IDENTIFICACIÓN DE LAS VÍCTIMAS DEL DESASTRE POR Huellas Dactilares: La Ruptura de la Presa de BRUMADINHO

Marco Antonio de Souza

Polícia Federal, Brasília/DF, Brasil desouza.mas@outlook.com

(9) http://lattes.cnpq.br/5337279717948592

\section{Gabriel de Oliveira URTiaga}

Polícia Federal, Porto Alegre/RS, Brasil gabriel.gou@pf.gov.br

(9) http://lattes.cnpq.br/4577304046150893

Flávio Roberto de melo Polícia Federal, Belo Horizonte/MG, Brasil flavio.frm@pf.gov.br

(9) http://lattes.cnpq.br/2708561950034310

Luciene Marques da Silva

Polícia Federal, Brasília/DF, Brasil marques.lms@pf.gov.br

(9) http://lattes.cnpq.br/3637387906974017 


\section{RESUMO}

Considerado o maior acidente de trabalho do Brasil, o rompimento da barragem de Brumadinho ocasionou grande impacto ambiental e elevado número de vítimas fatais (270), sendo caracterizado como um desastre de massa de grandes proporções. O resgate e a identificação das vítimas envolveram um enorme esforço coordenado entre forças de segurança pública. A Polícia Federal atuou de forma cooperativa, tendo se destacado no processo de identificação dos corpos. O presente estudo aborda o processo de identificação de vítimas de desastre através das impressões digitais, utilizando-se o Sistema Alethia. $\mathrm{O}$ uso desse sistema possibilitou a identificação de $47 \%$ das vítimas resgatadas e reduziu, consideravelmente, o tempo de resposta para suas famílias.

Palavras-Chave: impressão digital; DVI; Brumadinho/MG; Alethia; identificação humana; necropapiloscopia.

\section{ABSTRACT}

Considered the biggest accident at work in Brazil, the rupture of the Brumadinho dam caused a great environmental impact and a high number of fatalities (270), being characterized as a mass disaster of great proportions. The rescue and identification of the victims involved a massive coordinated effort between public security forces. The Federal Police acted cooperatively, having excelled in the process of identifying the bodies. The objective of this case study was to report the process of identification of the victims using fingerprints, in which the Alethia system was used. This System has contributed to $47 \%$ of fingerprint identifications and it has helped to cut the time required to this process.

KeYwORDS: Fingerprint; DVI; Brumadinho, MG; Alethia; human identification; necropapiloscopy.

\section{RESUMEN}

Considerado el mayor accidente de trabajo en Brasil, la ruptura de la presa Brumadinho causó un gran impacto ambiental y un alto número de muertes (270), siendo caracterizado como un desastre masivo de grandes proporciones. El rescate y la identificación de las víctimas implicaron un esfuerzo coordinado masivo entre las fuerzas de seguridad pública. La Policía Federal actuó de manera cooperativa, habiendo destacado en el proceso de identificación de los cuerpos. En este caso práctico se abordará el proceso de identificación por huellas dactilares, que tuvo el uso del sistema Alethia. Este sistema contribuyó al $47 \%$ de las identificaciones de huellas dactilares y considerablemente a la reducción del tiempo de respuesta para las familias de las víctimas.

Palabras clave: Huella dactilar; DVI; Brumadinho, MG; Alethia; identificación humana; Necropapiloscopia. 


\section{INTRODUÇÃo}

Em 1984, a Organização Internacional de Polícia Criminal (Interpol) produziu o primeiro guia para Identificação de Vítimas de Desastre (DVI), que tem sido revisado ao longo dos anos e fornece diretrizes para o gerenciamento de operações, alinhando ações diplomáticas, políticas e policiais, especialmente em operações multinacionais (INTERPOL, 2018).

Baseado no Guia da Interpol, foi elaborado, em 2011, por uma equipe multidisciplinar, o Manual de Identificação de Vítimas de Desastres da Polícia Federal (PF). Nesse, preconiza-se que em um evento de desastre com vítimas fatais, os restos humanos recuperados devem ser processados, examinados e armazenados em um necrotério, ou em um local construído temporariamente para a operação. A identificação é realizada por meio do cruzamento de todos os dados obtidos nas fases post mortem (PM) e ante mortem (AM). Os exames de PM incluem fotografias, análises de impressões digitais, odontológica, de DNA e, também, a autópsia. As informações AM envolvem a coleta de dados de pessoas desaparecidas por meio de entrevista com familiares, parentes ou amigos; busca por registros médicos e odontológicos, impressões digitais, DNA, documentos, fotografias e outros dados da vítima, quando ainda em vida, que possam contribuir para sua identificação (POLÍCIA FEDERAL, 2011).

Segundo a Interpol, desastres podem ser classificados como fechados, quando o número de mortos é conhecido e o grupo de fácil identificação, como desastres aéreos; ou abertos, quando eventos inesperados causam a morte de um número desconhecido de indivíduos, como o rompimento da barragem de Brumadinho, o que torna o desafio da identificação das vítimas ainda mais complexo. (INTERPOL, 2018).

O rompimento da barragem de Brumadinho ocorreu no dia 25 de janeiro de 2019, aproximadamente ao meio dia. Este evento é considerado como o maior acidente de trabalho e um dos maiores desastres ambientais do Brasil. Essa barragem de rejeitos de mineração, classificada como de baixo risco e de alto potencial de danos, localizava-se no ribeirão Ferro-Carvão, na região de Córrego do Feijão, no 
município de Brumadinho, a $65 \mathrm{Km}$ de Belo Horizonte - MG. A administração da barragem era de responsabilidade da empresa Vale S/A. Esse desastre de grandes proporções, despejou, de uma só vez, 12 milhões de metros quadrados de rejeito de mineração, afetando inicialmente uma área de 290 hectares e vitimando fatalmente 270 pessoas, entre funcionários da empresa Vale $\mathrm{S} / \mathrm{A}$, moradores da região e turistas (VALVERDE, 2019). Considerando a dimensão do desastre, para o processo de identificação das vítimas, a Secretaria de Segurança Pública do Estado de Minas Gerais contou com o apoio da Polícia Civil do Distrito Federal e da Polícia Federal.

O presente estudo de caso tem por objetivo apresentar as técnicas utilizadas nas identificações das vítimas do desastre com foco nas impressões digitais e destaque na utilização do sistema Alethia, cujo software foi desenvolvido pelo Instituto Nacional de Identificação (INI) da PF, sendo composto por um Sistema Automatizado de Identificação por Impressão Digital (AFIS) portátil e um kit biométrico.

\section{Metodologia}

Trata-se de levantamento de dados relativos aos processos de identificação por impressão digital das vítimas do desastre de Brumadinho, realizados com o uso do sistema Alethia, durante o período de 28 de janeiro a 26 de fevereiro de 2019. Os dados apresentados neste trabalho foram obtidos por meio de pesquisa aos arquivos de apresentações e relatórios produzidos para o INI da PF, que foram consultados no período de janeiro a fevereiro de 2021. Cabe destacar que os autores deste trabalho participaram da identificação das vítimas e foram responsáveis pela elaboração deste material consultado.

\section{Resultados e Discussóes}

Os trabalhos de identificação foram baseados nos protocolos estabelecidos pelo Manual de DVI/PF (POLÍCIA FEDERAL, 2011), segundo a seguinte rotina: os restos mortais eram resgatados da lama, levados de helicóptero a uma área onde um perito atuava no sentido de preservar as mãos e cabeça cobrindo essas regiões com sacos plásticos. Ainda nesta área, o corpo recebia uma numeração que o acompanhava 
durante todo o processo. Ao chegar no Instituto Médico Legal de Belo Horizonte, equipes de DVI recolhiam os dados PM. Assim, procedia-se a coleta de fotografias, de impressóes digitais e de material genético para exame de DNA. Em seguida, os corpos eram encaminhados à necropsia e para a realização de exames odontológicos. Paralelamente, equipes AM recolhiam material biológico de familiares e outras informações que pudessem auxiliar no processo de identificação. A Figura 1 representa a rotina estabelecida pelas equipes PM e AM.

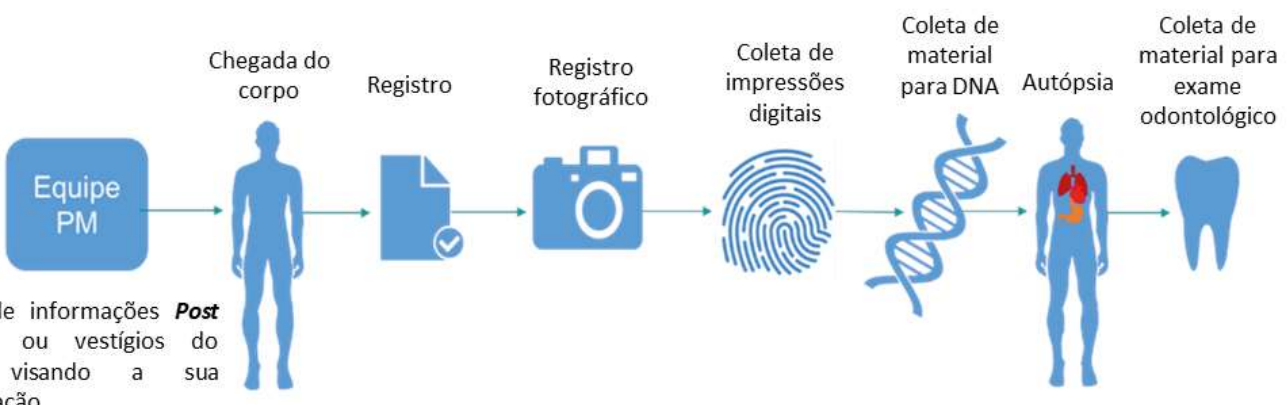

Mortem ou vestígios do

corpo visando a sua

identificação

$\begin{array}{cl}\text { Equipe } & \begin{array}{l}\text { Coleta de informações Ante } \\ \text { Mortem que possam INDICAR a }\end{array}\end{array}$

AM identidade de alguém

Figura 1: Representação esquemática da rotina estabelecida pelas equipes PM e AM no âmbito do processo de DVI.

O sucesso da identificação por impressões digitais depende do tipo de desastre que, por sua vez, terá influência direta no estado de conservação dos corpos. Neste caso, as vítimas foram encontradas em diferentes estados de decomposição, a maioria em processo de maceração e algumas com evidências de mumificação. Foram declaradas 270 pessoas desaparecidas, das quais 261 (96,7\%) foram identificadas pelas equipes de DVI. Desse total, a identificação por impressões digitais foi responsável por 74,7\%, (195). As outras identificações foram realizadas por equipes de odontologia forense, DNA e antropologia forense. Neste estudo de caso será apenas considerado o total das vítimas identificadas por impressões digitais

Desde o resgate dos corpos, havia grande preocupação com a preservação dos vestígios, em especial, das mãos para possibilitar o processo de identificação. A Figura 2 demonstra o procedimento adotado pelas equipes de DVI, ainda na área do resgate, para a preservação das impressões digitais a serem analisadas. Um invólucro plástico era utilizado para envolver as mãos, com o intuito de preservar os dedos e, eventualmente, a luva epidérmica, que poderiam cair e se perder no translado do corpo ao IML. 


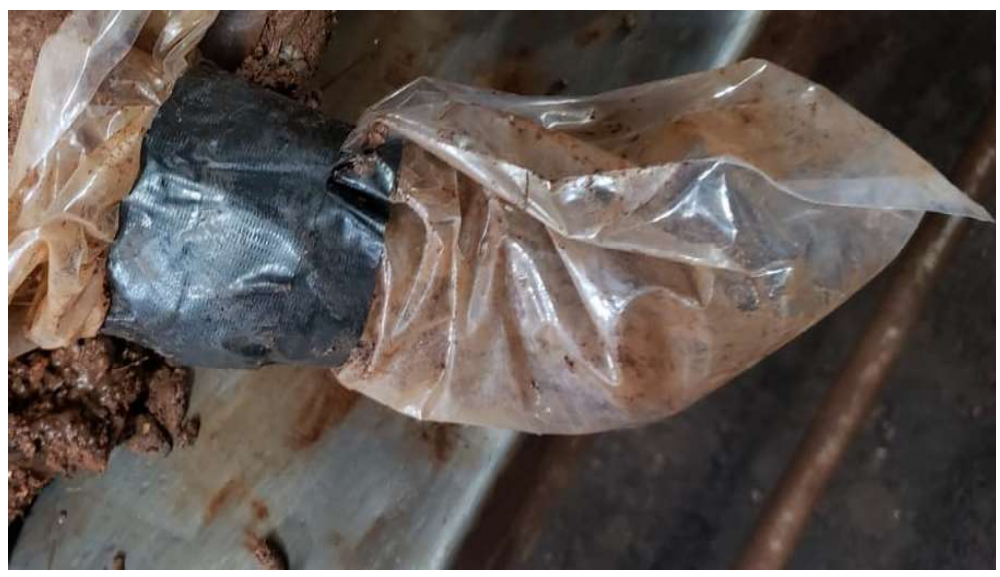

Figura 2. Imagem da mão de uma das vítimas resgatadas, preservada com um invólucro plástico (Fonte: Polícia Federal)

Uma vez que as vítimas foram soterradas pela onda de lama formada pelo rejeito de mineração, as mãos, de uma forma geral, apresentavam-se bastante sujas de lama, não sendo possível, em um primeiro momento, avaliar a qualidade técnica das impressões digitais para coleta, conforme demonstrado na Figura 3a. Dessa forma, era necessária a realização da lavagem das mãos das vítimas com água corrente $\mathrm{e}$ detergente para retirar a lama (Figura 3b.).

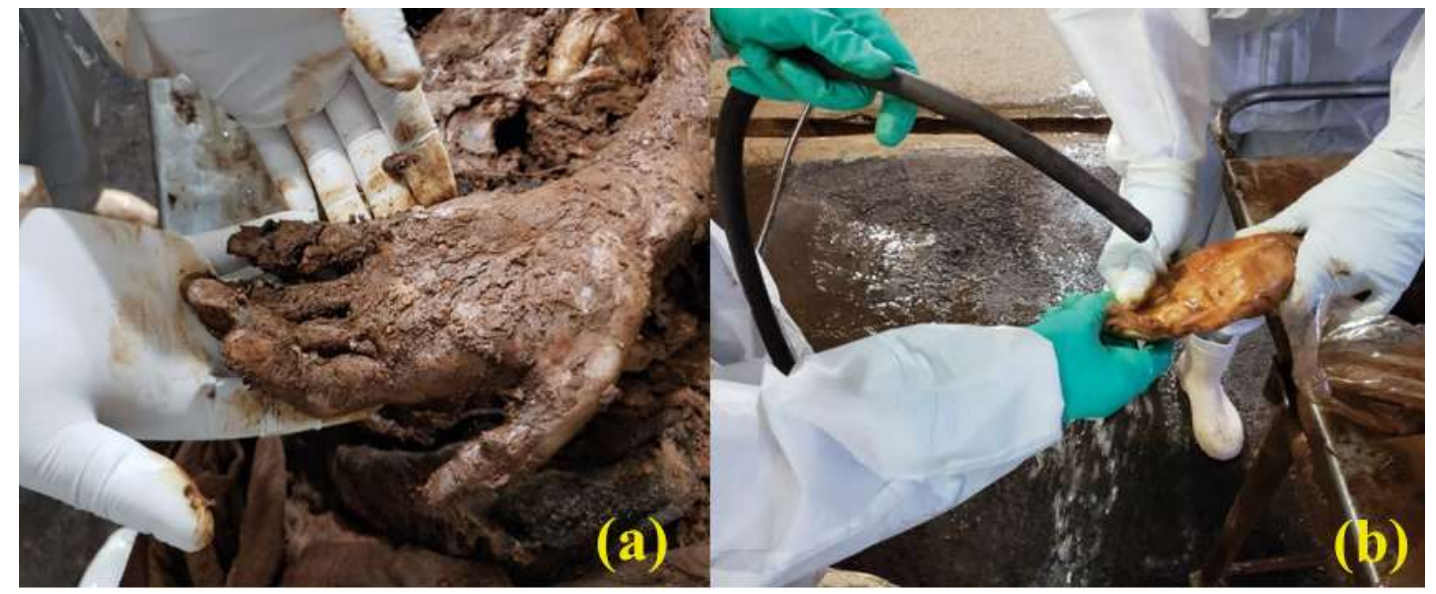

Figura 3. Imagens do procedimento de limpeza das mãos. (a) mãos sujas de lama e (b) lavagem das mãos das vítimas com água corrente e detergente para retirar a lama. (Fonte: Polícia Federal)

Dentre os exames necropapiloscópicos utilizados, em alguns casos, a extração e o calço da luva epidérmica (Figura 4a.) demonstrou ser o procedimento mais adequado para a realização da coleta das impressões digitais pelo Alethia, em outros, optou-se pelo método tradicional de tinta e papel. Nas mãos que não apresentavam detalhes papilares aparentes, utilizou-se a técnica da fervura ou ebulição (Figura 4b.) para provocar, por meio de respostas termodinâmicas e osmóticas, a hidratação da pele e eliminar os fluidos corporais resultantes do pro- 
cesso de decomposição. Essa técnica consiste em submeter a mão do cadáver à água fervente $\left(100^{\circ} \mathrm{C}\right)$ por alguns segundos (KIM; PARK; EOM, 2007, DELGADO; MARIOTTI, 2020).

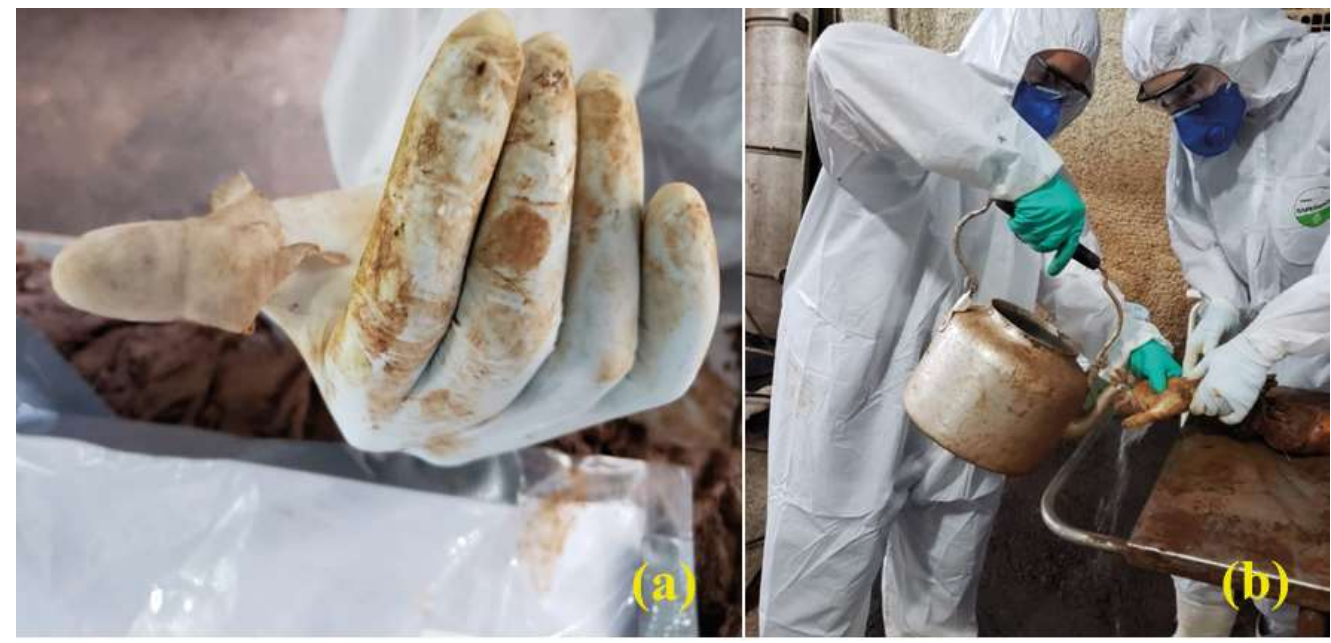

Figura 4. Imagem da luva epidérmica calçada na mão do perito papiloscopista para a realização da coleta das impressões digitais pelo Alethia, ou pelo método tradicional de tinta e papel (a). Aplicação da técnica da fervura ou ebulição para provocar, por meio de respostas termodinâmicas e osmóticas, a hidratação da pele e eliminar os fluidos corporais resultantes do processo de decomposição (b). (Fonte: Polícia Federal)

Caso fosse visualmente constatada a qualidade técnica adequada das impressões digitais, realizava-se a coleta diretamente por meio do Alethia (Figura 5a). Uma vez carregadas as impressóes digitais padrão no banco de dados do sistema, a identificação era feita em cerca de 2 segundos (Figura 5b).

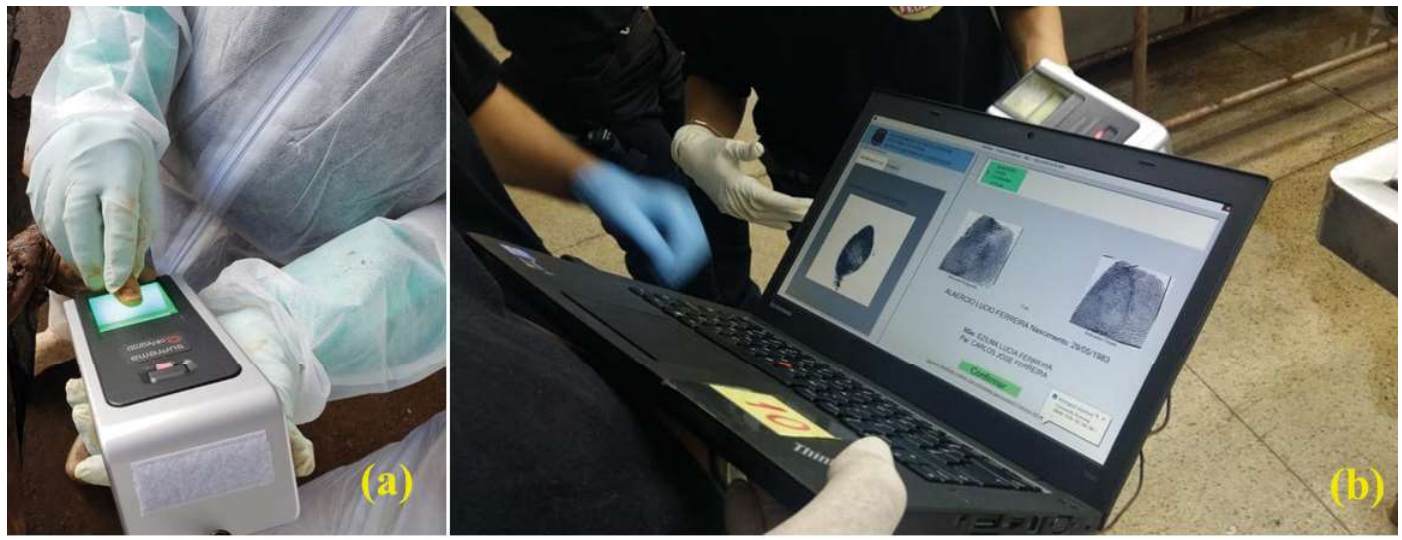

Figura 5 Imagens da tentativa de coleta de impressão digital, na camada da derme do dedo polegar esquerdo, do segmento analisado(a) e do resultado da identificação no Alethia (b)

(Fonte: Polícia Federal)

A identificação de vítimas de desastres por impressões digitais, com auxílio de um sistema biométrico portátil não é novidade. Em 2006, foi registrada uma patente americana de um aparelho com as ca- 
racterísticas de um AFIS portátil. Kits eletrônicos de coleta de impressões digitais foram testados para coleta em alguns acidentes, anos anteriores ao desastre de Brumadinho (JOHNSON; RIEMEN, 2019).

O Alethia é um equipamento composto por um notebook, um leitor biométrico para coleta de impressões digitais, um banco de dados pré-carregado com os padróes das vítimas e um software que compara as impressões digitais coletadas com as impressões digitais padrão, conforme visto na Figura 6. O sistema Alethia foi desenvolvido como ferramenta para auxiliar o esquema de segurança dos jogos olímpicos no Brasil (2016) e utilizado para identificar foragidos internacionais, integrantes da lista vermelha da Interpol, em aeroportos brasileiros. Foi usado pela primeira vez para fins necropapiloscópicos, na identificação das vítimas do desastre aéreo da empresa Lamia, que conduzia a equipe de futebol Chapecoense e caiu na Colômbia, em 2016. 


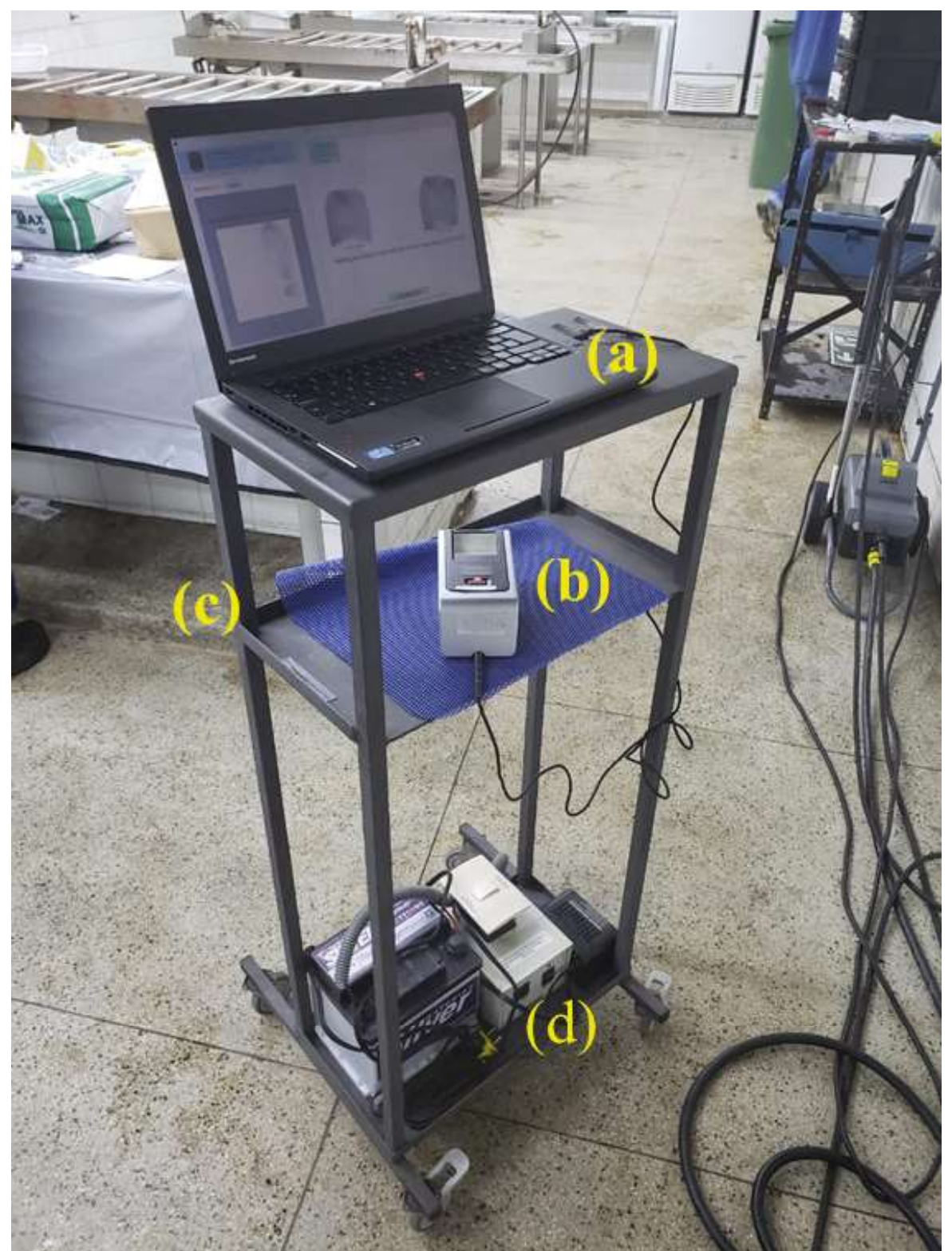

Figura 6. Imagem do sistema Alethia utilizado no IML da cidade de Belo Horizonte durante a missão em Brumadinho formado pelos seguintes componentes: a) notebook; b) leitor biométrico; c) estante com rodas; d) bateria (Fonte: Polícia Federal).

No que se refere ao trabalho realizado após o acidente de Brumadinho, por tratar-se de um desastre aberto, os padrões de impressões digitais das vítimas foram carregados no Alethia, à medida em que eram obtidos pela equipe AM. Ainda assim, o sistema era utilizado para a coleta, dispensando a utilização de técnicas tradicionais, como microadesão, moldes de silicone, etc. As impressões digitais dos indivíduos não identificados coletadas no Alethia eram enviadas pela internet, pelo próprio sistema, ao Grupo de Identificação da Superintendência da PF de Minas Gerais, na cidade de Belo Horizonte, para serem confrontadas no AFIS nacional. 
Considerando o período no qual as equipes de DVI utilizaram o sistema Alethia, compreendido entre os dias 28 de janeiro e 26 de fevereiro de 2019, foram identificadas 185 vítimas. Destas, a análise de impressões digitais foi responsável por $85,6 \%$ das identificações realizadas, em comparação com os demais métodos primários. Em $0.5 \%$ dos casos, a análise de impressões digitais atuou em conjunto com o DNA para confirmar a identificação de vítimas e, em $2,7 \%$ dos casos, com a análise odontológica. Cabe ressaltar que, posteriormente, foram identificadas as demais vítimas, chegando-se ao total de 261, das quais 195 por impressões digitais. Ressalta-se que esse total não será aqui abordado, uma vez que o foco é a comparação da utilização do sistema Alethia.

Para uma melhor compreensão da atuação do sistema Alethia, dividiu-se os resultados das identificações pelo sistema em direto e indireto. Identificações diretas foram definidas como as positivações realizadas no IML, logo após a coleta da impressão digital, realizada diretamente no leitor biométrico. Já as identificações indiretas foram aquelas nas quais o sistema foi capaz de capturar as imagens das impressões digitais, nesse caso, suas positivações só ocorreram após serem incluídas e pesquisadas no sistema AFIS nacional da PF.

Das identificações realizadas com o uso do Alethia, $30 \%$ foram identificações diretas, sendo o restante identificações indiretas ou com o uso de exames necropapiloscópicos tradicionais, como microadesão, moldagem e entintamento. Considerando as identificações diretas e indiretas realizadas pelo sistema Alethia, um total de $47 \%$ das vítimas foram identificadas por esse método. O detalhamento do total de vítimas identificadas por impressões digitais nas diferentes metodologias encontra-se na Tabela 1.

Tabela 1. Número de vítimas identificadas por impressões digitais no período de 28 de janeiro a 26 de fevereiro de 2019 e total por técnica utilizada.

\begin{tabular}{|c|c|c|}
\hline $\begin{array}{c}\text { Total de vítimas } \\
\text { identificadas através }\end{array}$ & \multicolumn{2}{|l|}{158} \\
\hline \multirow{3}{*}{$\begin{array}{c}\text { Total por técnica } \\
\text { utilizada }\end{array}$} & Identificação direta pelo sistema Alethia & $47(30 \%)$ \\
\hline & $\begin{array}{c}\text { Coleta com o sistema Alethia e identificação } \\
\text { no AFIS nacional da PF }\end{array}$ & $27(17 \%)$ \\
\hline & $\begin{array}{l}\text { Identificação por exames necropapiloscópi- } \\
\text { cos tradicionais }\end{array}$ & $84(53 \%)$ \\
\hline
\end{tabular}

As identificações que não foram realizadas diretamente pelo 
Alethia, podem ser explicadas por dois motivos, quais sejam: pela inserção de padróes (individuais datiloscópicos) com baixa qualidade técnica para um confronto no banco de dados do sistema ou pela ausência de prontuários das vítimas. Por tratar-se de um desastre aberto, no qual as vítimas não são previamente conhecidas em sua totalidade, o banco do Alethia era diariamente atualizado com novas informações de pessoas desaparecidas fornecidas pela equipe AM. Ademais, a questão da falta de qualidade técnica dos padrões ainda é um desafio enfrentado pelas instituições responsáveis pela coleta de impressões digitais civis.

Cabe salientar que a identificação de uma vítima pelo sistema Alethia dura, em média, 2 segundos, enquanto a utilização de outros métodos tradicionais para coleta pode durar vários minutos. Considera-se que todo o processo de DVI é de suma importância para garantir aos familiares das vítimas o direito de prestarem suas últimas homenagens, sendo uma forma de redução do sofrimento da perda e processamento do luto. Assim, uma identificação ágil torna-se um desafio neste tipo de evento. Mais que uma missão policial, o trabalho de identificação de vítimas em desastres em massa é uma missão humanitária que a Polícia desempenha.

Por fim, observa-se que as impressões digitais coletadas para documentos válidos no Brasil (Registro Geral, Passaporte etc.) são armazenadas em bancos de dados ou em arquivos físicos dactiloscópicos. Esse processo é de grande valia para fins de DVI, pois, possuir padrões para comparação a pronto emprego torna a identificação mais rápida, uma vez que outros métodos primários de identificação podem ter complicações próprias, principalmente quando se trata de um desastre aberto.

\section{Conclusão}

Como foi demostrado, a utilização do sistema Alethia para a identificação necropapiloscópica traz como grande vantagem a redução de tempo nesse processo, possibilitando a identificação de uma vítima em aproximadamente 2 segundos. Destaca-se que a agilidade no processo de identificação tem importante papel social, haja vista que proporciona aos familiares a possibilidade de prestar suas últimas homenagens, contribuindo para a diminuição do tempo de incerteza. 
Vale ressaltar, ainda, que a agilidade e a precisão do método de identificação por meio das impressões digitais é uma escolha assertiva da equipe de DVI, nos casos em que as papilas dérmicas estiverem preservadas e apresentarem condições técnicas para a identificação. No entanto, nos casos em que o estado dos corpos não permitirem a coleta de digitais, outros métodos de identificação humana devem ser avaliados, tais como como o exame de DNA e as análises dentárias.

BIOGRAFIA DO(A)S AUTORE(A)S:

Marco Antonio De Souza

Papiloscopista Policial Federal (Instituto Nacional de Identificação - Polícia Federal)

Mestre em Nanociência e Nanobiotecnologia

(UNIVERsidade de Brasília)

Doutorando em Nanociência e Nanobiotecnologia

(UNiversidade de Brasília)

Pesquisador e lider do Grupo de Pesquisa Papiloscopia Forense (Academia Nacional de Polícia).

Membro do Grupo de Pesquisa Nanotecnologia VERDE: AMBIENTE, SAÚDE E SUSTENTABILIDADE

(UNIVERSIDAde de Brasília).

\section{Gabriel de Oliveira Urtiaga}

Papiloscopista Policial Federal, lotado no Núcleo de Identificação da Superintendência da Polícia Federal no Rio Grande do Sul.

Graduado em Ciências Biológicas (UCPel), Especialista em Identificação Humana (ANP/PF) Mestre em Biotecnologia (UFPel)

\section{Flávio Roberto de Melo}

Possui graduação em Direito pela Faculdade de Negócios de Belo Horizonte (2010) E graduaÇão em Administração pela Faculdade CECAP (2003).

Papiloscopista Policial Federal, lotado no Núcleo de IDENTIFICAÇÃO DA

Superintendência Regional de Polícia Federal de Minas Gerais 
Luciene Marques da Silva

Possui graduação em Direito pela Faculdade

Processus (2014).

Papiloscopista Policial Federal lotada no Instituto Nacional de IDentificaÇão da Polícia

Federal.

\section{REFERÊNCIAS}

DELGADO, S; MARIOTTI, K. Métodos de identificação humana Post Mortem em necropapiloscopia: revisão da Literatura. Revista Brasileira de Ciências Policiais, v. 11, n. 3, p. 349-383, 2020.

INTERPOL. Disaster Victim Identification Guide. Lion, 2018. .

JOHNSON, B. T.; RIEMEN, J. A. J. M. Digital capture of fingerprints in a disaster victim identification setting: a review and case study. Forensic Sciences Research, v. 4, n. 4, p. 293-302, 2019. DOI: $10.1080 / 20961790.2018 .1521327$. Disponível em: https:// doi.org/10.1080/20961790.2018.1521327.

KIM, YOUNG-SAM; PARK, HEE-CHAN; EOM, Y. B. The High Temperature-Moisturizing Method for Obtaining Quality Postmortem Fingerprints from Decomposed Fingers.pdf. J. Exp. Biomed Sci, v. 13, p. 369-374, 2007.

POLÍCIA FEDERAL. Manual de Identificação de Vitimas de Desastres. [S. l.: s.n.], 2011.

VALVERDE, R. Desastre da Vale. 2019. Disponível em: https:// agencia.fiocruz.br/desastre-da-vale. 


\section{INFORMAÇÕES ADICIONAIS E DECLARAÇÕES DOS AUTORES}

\section{(integridade cientifica)}

Declaração de conflito de interesse: $\mathrm{O}(\mathrm{s})$ autor(es) confirma(m) não haver conflitos de interesse na condução desta pesquisa e na redação deste artigo.

Declaração de autoria: Todos e apenas os pesquisadores que atendem os requisitos de autoria deste artigo são listados como autores; todos os coautores são integralmente responsáveis por este trabalho em sua totalidade.

Declaração de originalidade: $\mathrm{O}(\mathrm{s})$ autor(es) assegura(m) que o texto aqui publicado não foi previamente divulgado em qualquer outro local e que a futura republicação apenas será feita com expressa referência desta publicação original; também atesta $(\mathrm{m})$ que não há plágio de material de terceiros ou autoplágio.

\section{Como Citar (Abnt BrasiL)}

SOUZA, Marco Antonio de; URTIAGA, Gabriel de Oliveira; MELO, Flavio Roberto de; SILVA, Luciene Marques da. Identificação de vítimas de desastre pelas impressões digitais: O rompimento da barragem de Brumadinho. Revista Brasileira de Ciências Policiais, Brasília, vol. 13, n. 7, p. 337-350, jan./abr. 2022.

https://doi.org.br/10.31412/rbcp.v13i7.839

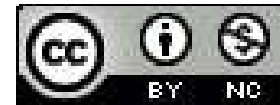

Esta obra está licenciada com uma Licença Creative Commons Atribuição-NãoComercial 4.0 Internacional. 